\title{
Approaches to Tariffs Formation for Ethylene by Pipelines Transportation
}

\author{
Kulikova L.I.a \\ Sokolov A.Y.b \\ Ivanovskaya A.V.c \\ a bc Kazan Federal University, Institute of Management, Economics and Finance, Kazan, 420008, Russia \\ Email: anna_ivanovski@mail.ru
}

\section{Doi:10.5901/mjss.2015.v6n1s3p416}

\section{Abstract}

The paper suggests two approaches to formation of tariffs for ethylene by pipeline transportation. These approaches consider technological features of ethylene pipeline application and ensure differentiation of tariffs for different users depending on the type of the commodity transport work fulfilled for ethylene pumping. Application of double rate tariffs for services of ethylene transportation via ethylene pipeline is recommended. Double rate tariff includes both tariff rate for ethylene pipeline use, which is uniform for all consumers, and tariff rate for the work fulfilled for ethylene pumping, which depends on the planned volume of commodity transport work for ethylene transfer under the contract with the services consumer.

Keywords: tariff, costs, ethylene transportation, rate for use, rate for pumping

\section{Introduction}

Pumping via ethylene-pipeline is the most optimal alternative of ethylene transportation from the standpoint of costs minimizing. In the most general terms, the process of ethylene pumping can be compared with transportation of gas via pipeline: in both cases there occurs pumping of gaseous substance via pipeline transport.

The process of price formation for gas transportation services in Russia is strictly under the government control: tariffs calculating methodology for gas transportation service is protected by law.

Tariffs for ethylene pumping service in Russia are not regulated by the state. Technological features of ethylene pumping process do not allow direct application of methodology for calculating tariffs for gas transportation services. Therefore, the organizations involved in transportation of ethylene via ethylene pipeline system face the acute problem of developing methods of pricing for services of ethylene pumping, with consideration of consumers' interests in these services. This fact determines the relevance of this study, theoretical and practical value of its results.

The research works of Borenstein, S. and R. Kellogg [1], Ulvestad, M. and J. Overland [2], Secomandi, N. [3], Pienaar, W.J. [4], Lawrey, R. [5], Smith, D. and S.W. Moses [6] were dedicated to pricing issues of pipeline transport services. However, the scientific publications do not consider the peculiar features of tariffs formation for ethylene pumping.

The aim of the research is to develop approaches to formation of economically justified tariffs for transportation of ethylene by pipeline.

\section{Method}

In developing the procedure of tariffs formation for ethylene pumping services it is necessary to base on the following peculiar features of ethylene-line operation:

- ethylene pipeline connects ethylene producers with ethylene consuming enterprises, and therefore it includes several shops located in the cities of the mentioned enterprises location;

- transportation of ethylene occurs in the supercritical mode, which prevents ethylene from formation of liquid phase in the pipeline and from the hydraulic shock, which may lead to large release of ethylene in the atmosphere. This mode is ensured by maintaining the required level of pressure throughout the entire system of ethylene pipeline; so the process of ethylene pumping via the particular section is provided not only by the 
work of shops servicing the given site directly, but also by the other shops.

Thus, in connection with the above mentioned technological features of ethylene pumping, the whole ethylene pipeline should be regarded as a single technological complex. The operation of this complex as a whole is needed for the ethylene pumping opportunity regardless of its direction and distance. This fact principally distinguishes the system of ethylene pipeline from gas pipeline system and, of course, must be taken into account, when developing methods of tariffs formation for ethylene pumping services.

Since Ethylene pipeline is a unified technological complex, we believe it reasonable to account the costs of ethylene transportation in a single calculation and determine the tariff for ethylene pumping services per 1 ton basing on the entire amount of costs incurred by the transporter distributed for this service.

Transportation of ethylene to consumers is a service having no material real-valued form. This is the reason of using the following physical units for calculation at the enterprises of the given industry:

- volume of ethylene pumping in tons;

- volume of commodity transportation work in ton-kilometers.

The averaged tariff for service of a ton of ethylene pumping (AT) is calculated by the formula:

$A T=(C+P) / V$,

where $\mathrm{C}$ - is economically justified planned costs for ethylene pumping service;

$P$ - planned amount of profit on ethylene pumping service;

$V$ - volume of planned pumping of ethylene for all consumers in tons.

The amount of planned costs and planned profit for ethylene pumping service is the necessary revenue of ethylene organization - transporter. Using the necessary revenue for the purposes of pricing is reflected in the works of Pikk, P. and M. Viiding [7], Briest, P., Chawla, S., Kleinberg, R., and S.M. Weinberg [8], Kulikova, L.I. and A.V. Goshunova [9], Li, Y., Miao, Q. and B.X. Wang [10].

If the route of ethylene pumping is the same for all consumers, i.e. the system of ethylene pipeline is serviced only by two workshops: the consigner and the consignee of ethylene, then the average tariff for ethylene pumping service will be the unified for all consumers and calculated per 1 ton of ethylene pumping.

If the difference by the contracts with customers on pumping ethylene service is not only in planned volumes of ethylene transportation, but in pumping distances as well, then in order to achieve economic justice it is advisable to distribute part of the costs in calculation of tariff in each direction of transport of ethylene proportionally to the fulfilled commodity transportation work. In this case, the use of double rate tariff for services on transportation of ethylene is justified. It consists of tariff rate for the use of ethylene ( $\left.R_{u}\right)$ (fixed for all consumers) and tariff rate for ethylene pumping $\left(R_{p}\right)$ (taking into account commodity transportation work of ethylene pumping). The idea of the multi-component tariffs for transportation service establishing urgency is supported by Street, A., Barroso, L.A., Chabar, R., Mendes, A.T.S. and M.V. Pereira [11], De Vany, A.S., and W.D. Walls [12].

The tariff rate for ethylene pipeline use is a basic one; it does not depend on the distance of ethylene transportation and is calculated on the basis of the planned volume of ethylene pumping for all consumers. The tariff rate for the work done on ethylene pumping is calculated per ton-kilometer of the pumped ethylene. This tariff rate depends on the volume of commodity transportation work influenced by the combination of two factors: the amount of ethylene pumping and transportation distance.

The tariff for ethylene pumping service for the particular consumer $\left(T_{i}\right)$ will be calculated by the formula:

$\mathrm{T}_{\mathrm{i}}=\mathrm{R}_{\mathrm{u}}+\mathrm{R}_{\mathrm{p}} \times \mathrm{Li}_{\mathrm{i}}$

where $\mathrm{L}_{i}$ - is the distance of ethylene transportation for the i-th user.

The following formulas are applied to calculate rates for the use of ethylene $\left(R_{u}\right)$, and for movement of ethylene $\left(R_{p}\right)$ :

$\mathrm{R}_{\mathrm{u}}=\mathrm{RRV} / \mathrm{V}$,

$\mathrm{R}_{\mathrm{p}}=\mathrm{RR}_{\mathrm{T}} \mathrm{Tw} / \mathrm{CTW}$,

where RRv - is the part of necessary revenue distributed among consumers of services in proportion to the volume of ethylene pumping;

RRctw - is the part of necessary revenue distributed between service consumers proportionally to commodity transport work;

CTW - is the planned value of commodity transportation work under contracts with all service users on ethylene pumping (in ton-kilometers).

The main problem lies in the reasonable division of the necessary revenue of ethylene transporter into two components: RRv and RRcrw, used to calculate the components of dual rate tariff. We solve this problem by using the method of expert assessment of the averaged rate components to determine their relationship with the volume of fulfilled 
commodity transportation work and with the technology of ethylene pumping.

\section{Result}

The enlarged structure of the averaged tariff for ethylene pumping is presented by the following items:

- direct expenses of ethylene pumping;

- production expenses;

- general expenses;

- business expenses;

- profit. services.

The research led us to the development of two approaches to formation of double rate tariff for ethylene pumping

Approach I. Key grouping of costs in determining the basis of their distribution among consumers: dependent and independent on the volume of commodity transportation work.

The tariff rate for ethylene pipeline use is determined on the basis of expenses, the value of which does not depend on the volume of commodity transportation work. These expenses include:

- part of direct expenses not depending on the volume of commodity transportation work;

- production expenses;

- general expenses;

- business expenses.

Production, general and business expenses, as a rule, are of conditional permanent nature in relation to the volume of commodity transportation work. They are associated with ethylene pipeline use as a single technological complex. Inherently, these are production and non-production costs to maintain the system in the state of readiness to accept ethylene by the buyers.

Tariff rate for the fulfilled work on ethylene pumping is determined on the basis of:

- planned expenses, depending on the volume of commodity transportation work (i.e. volume of ethylene pumping and distance of transportation);

- amount of planned profit, which depends on the volume of commodity transportation work.

- The costs depending on the volume of commodity transportation work include:

- material costs in terms of ethylene loss during pumping;

- the cost of electricity required for the process of ethylene pumping.

Planned profit is calculated on the basis of the principle of equal rate of profit per ton-kilometer. This is stipulated by the fact that the profit is effected by change in volume of commodity transportation. The greater the volume of pumping and transport distance, the more profit the ethylene transporting organization will receive, so the profit is distributed among consumers of ethylene pumping service proportionally to commodity transportation work done.

The scheme of formation of double rate tariff for ethylene pumping service basing on this approach is shown in Figure 1.

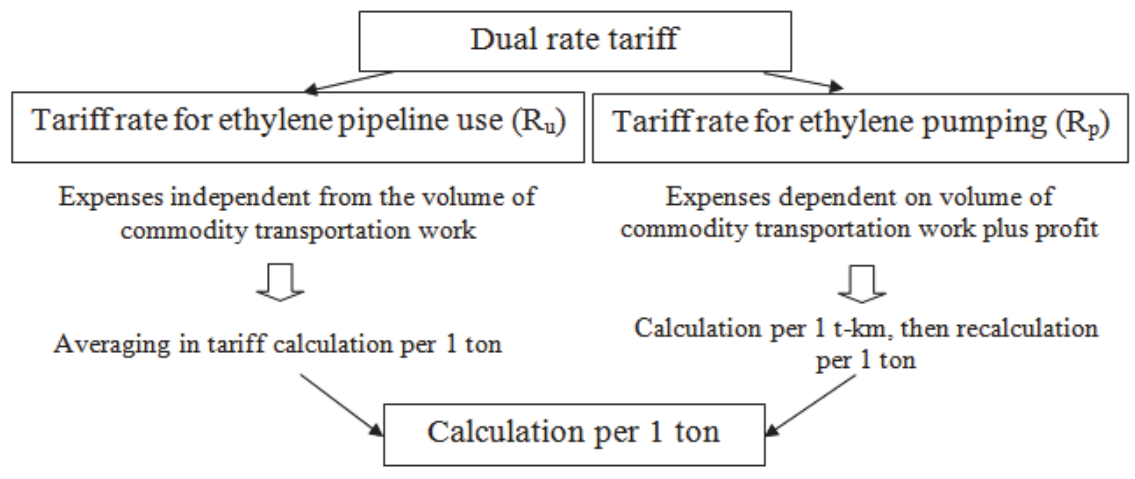

Fig. 1. The double rate tariff for ethylene pumping service (approach I)

Approach II. The volume of the of ethylene transporting organization's activity are expressed in commodity transportation 
work done on ethylene pumping; thus, reasonable is the distribution of components of necessary revenue from the provision of ethylene pumping services between consumers proportionally to the planned commodity transportation work.

However, the transporter of ethylene incurs some of the expenses for providing technical possibility of pumping process fulfillment regardless of pumping distance, so these expenses should be borne by all consumers of services in transportation of ethylene depending on the volume of its pumping, and they cannot be distributed on commodity transportation work.

Therefore, it is necessary to distinguish two components in the structure of the averaged tariff:

- related to the process of ethylene pumping (production expenses);

- not related to the process of ethylene pumping (general expenses, business expenses, profit).

In its turn, the costs associated with process of ethylene pumping include the one that are dependent and independent on commodity transportation work done.

Costs depending on commodity transportation work done should be distributed among consumers of ethylene pumping proportionally to commodity transportation work as they are conditioned by the quantity of ton-kilometers of ethylene pumped.

Costs associated with the process of ethylene pumping, but independent of commodity transportation work represent the sum of charges for ethylene pipeline servicing as a single technological complex and the variable costs, which depend only on the amount of ethylene pumping. These costs should be distributed between consumers of ethylene pumping services in proportion to the volume of the pumped ethylene.

Components of the averaged tariff not related to the technology of ethylene pumping, are distributed among consumers of ethylene pumping service proportionally to the commodity transportation work done (Fig. 2).

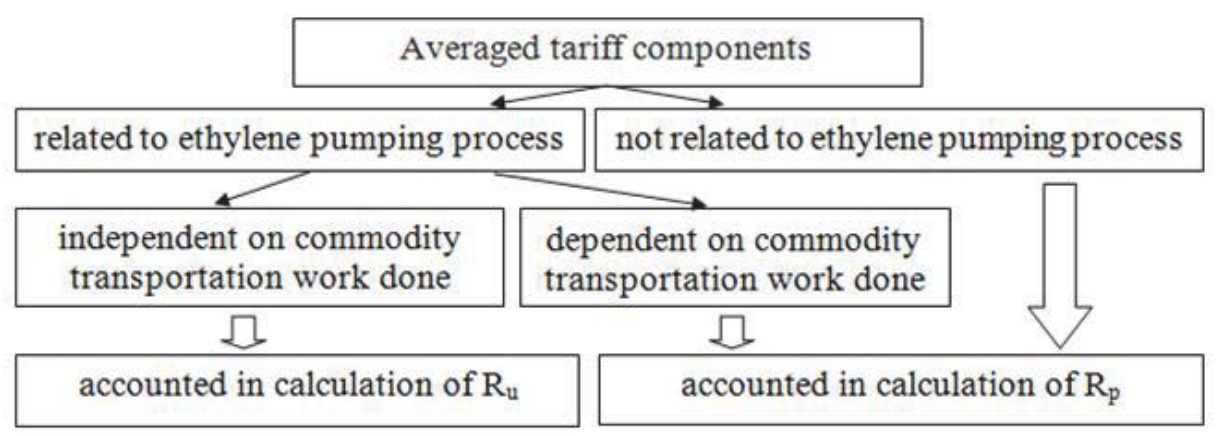

Fig. 2. Components of the averaged tariff and the procedure of their distribution among consumers of ethylene pumping service (approach 2)

Table 1 presents the structure of the averaged tariff and the procedure of its components distribution between the consumers of ethylene transportation services within the scope of our proposed approach application to formation of tariffs for ethylene pumping services.

Table 1. Structure of the averaged tariff for ethylene pumping service and the basis of its components distribution between the consumers

\begin{tabular}{|l|c|c|}
\hline \multirow{2}{*}{ Items } & \multicolumn{2}{|c|}{ Basis of distribution between the consumers } \\
\cline { 2 - 3 } & Approach I & Approach II \\
\hline $\begin{array}{l}\text { Direct expenses, including: } \\
\text { Dependent of CTW } \\
\text { Independent of CTW }\end{array}$ & $\begin{array}{c}\text { CTW } \\
\text { Volume }\end{array}$ & $\begin{array}{c}\text { CTW } \\
\text { Volume }\end{array}$ \\
\hline Production costs & Volume & Volume \\
\hline General costs & Volume & CTW \\
\hline Business costs & Volume & CTW \\
\hline Profit & CTW & CTW \\
\hline Total averaged tariff & $\mathrm{x}$ & $\mathrm{x}$ \\
\hline
\end{tabular}




\section{Conclusion}

Our proposed approaches to formation of tariffs for ethylene pipeline transportation service consider the interests of these services' consumers, since they provide for redistribution of the averaged tariff depending on the commodity transportation work done. Thus, as it is shown in the data of the Table 1, the latter approach provides the greater degree of differentiation of tariffs for different users depending on the distance of ethylene transportation. As disadvantage of both approaches it should be noted that in practice it is quite difficult to determine the exact amount of costs which depend on commodity transport work done.

\section{References}

Borenstein, S., Kellogg, R. The incidence of an oil glut: Who benefits from cheap crude oil in the midwest? // Energy Journal 35 (1), 2014. pp. 15-33.

Ulvestad, M., Overland, I. Natural gas and $\mathrm{CO}_{2}$ price variation: Impact on the relative cost-efficiency of LNG and pipelines // International Journal of Environmental Studies 69 (3), 2012. pp. 407-426.

Secomandi, N. On the pricing of natural gas pipeline capacity // Manufacturing and Service Operations Management 12 (3), 2010. pp. 393-408.

Pienaar, W.J. The regulation of commercial petroleum pipeline operations: A South African example // Corporate Ownership and Control 7(3), 2010. pp. 188-192.

Lawrey, R. Pricing and access under national competition policy: the case of the natural gas pipeline sector // Australian Economic Review 31 (2), 1998. pp. 91-106.

Smith, L.D., Moses, S.W. Strategic planning of transportation services for petroleum products An application of capacitated gravity models // European Journal of Operational Research 88 (2), 1996. pp. 215-230.

Pikk, P., Viiding, M. The dangers of marginal cost based electricity pricing // Baltic Journal of Economics 13 (1), 2013. pp. 49-62.

Briest, P., Chawla, S., Kleinberg, R., Weinberg, S.M. Pricing lotteries // Journal of Economic Theory, 2014.

Kulikova, L.I., Goshunova, A.V. Efficiency measurement of professional football clubs: A non-parametric approach // Life Science Journal 11 (SPEC. ISSUE 11), 2014. pp. 117-122.

Li, Y. Miao, Q., Wang, B.X. Modeling a cruise line revenue management problem // Journal of Revenue and Pricing Management 13 (3), 2014. pp. 247-260.

Street, A., Barroso, L.A., Chabar, R., Mendes, A.T.S., Pereira, M.V. Pricing flexible natural gas supply contracts under uncertainty in hydrothermal markets // IEEE Transactions on Power Systems 23 (3), 2008. pp. 1009-1017.

De Vany, Arthur S., Walls, W. David Open access to rail networks // Transportation Quarterly 51 (2), 1997. pp. 73-78. 